\title{
Recent Approaches in Poultry Breeding
}

\author{
Thiruvenkadan $\mathrm{AK}^{1 *}$ and Prabakaran $\mathrm{R}^{2}$ \\ ${ }^{1}$ Mecheri Sheep Research Station, India \\ ${ }^{2}$ Tamil Nadu Veterinary and Animal Sciences University, India \\ *Corresponding author: AK Thiruvenkadan, Mecheri Sheep Research Station, Tamil Nadu, India

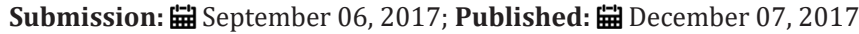

Keywords: Computed tomography; Soft and exudative; Crooked toes; Long bones; Firm and dry meat

Abbreviations: CT Scan: Computed Tomography Scan; MRI: Magnetic Resonance Imaging; DFD: Dark, Firm and Dry; PSE: Pale, Soft and Exudative; NFкB: Nuclear Factor Kappa-B; EGCG: Epigallocatechin-3-Gallate; LB: Long Bones; CT: Crooked Toes; TD: Tibial Dyschondroplasia; HPAI: Highly Pathogenic Avian Influenza; PN: Programmed Nutrition

\section{Introduction}

Table 1:

\begin{tabular}{|c|c|}
\hline Technique & $\begin{array}{c}\text { Decade of Introduction } \\
\text { (Approx.) }\end{array}$ \\
\hline Mass selection & 1900 \\
\hline Trapnesting & 1930 \\
\hline Hybridization & 1940 \\
\hline Pedigreeing & 1940 \\
\hline Artificial insemination & 1960 \\
\hline Osborne index & 1960 \\
\hline Family feed conversion testing & 1970 \\
\hline Selection index & 1980 \\
\hline Individual feed conversion testing & 1980 \\
\hline BLUP breeding value estimation & 1990 \\
\hline DNA markers & 2000 \\
\hline Arthur and Albers & \\
\hline
\end{tabular}

The domestication process of wild jungle fowl marked the start of selective breeding of poultry. Over the millennia many different breeds were developed and by the end of the nineteenth century AD many breeds were in existence. These showed marked differences between breeds and homogeneity within them for a range of traits, including production traits such as body size, musculature, egg production and egg colour. Some of these breeds were the basis of industrial poultry breeding as we know it today: White Leghorn, Rhode Island, Cornish Game and Plymouth Rock, to name the most important ones. Industrial breeding commenced with the hybridization of selected pure breeding lines sampled from these base breeds and continued with more and more intense further selection of the pure lines. As time progressed and competition between breeding companies intensified, the methods used in the genetic selection process applied to the pure lines were increasingly based on science. The major traits are improved by positive selection (high intensity), which is regenerated from the best families. Minor traits such as fertility, hatchability and livability are improved by eliminating the few worst families (low intensity). The breeding companies utilized different breeding and selection technologies at different period of time for the genetic improvement of poultry. They were as follows: (Table 1).

Quantitative genetic methods effectively regard the bird as a black box with many genes contributing to the expression of all traits under selection. Molecular genetics is now opening this black box by elucidating the effect of single genes on the phenotypic expression of traits. As breeding deals with identifying and exploiting the genetic basis of phenotypes, there is no doubt whatsoever that the use in breeding of knowledge of molecular genetics, i.e., molecular breeding, will totally change our current practices of selective breeding in poultry breeding. In addition, it is likely to also affect the role of the poultry breeding industry in poultry production. This paper will give a short overview of the nature and impact of the methods introduced until now. It will then focus on the impact of breeding methods derived from molecular genetics on the future of poultry breeding.

\section{Genetic Strategies for the Improvement of Broilers}

Breeders set breeding goals as a reflection of their expectations of future market demands with the ongoing changes of production and consumption trends. Global trend on breeding goals since the early 1950s have been as follows: (Table 2). 
Table 2:

\begin{tabular}{|c|c|c|c|}
\hline Selection Trait & 1975-1985 & 1985-1995 & 1995-2002 \\
\hline $\begin{array}{c}\text { Hatching egg } \\
\text { production }\end{array}$ & +++ & ++ & + \\
\hline Fertility & + & + & + \\
\hline Broiler growth rate & +++ & +++ & +++ \\
\hline Broiler feed efficiency & ++ & +++ & +++ \\
\hline Meat yield traits & + & ++ & +++ \\
\hline Livability & + & + & ++ \\
\hline \multicolumn{4}{|c}{ Arthur and Albers } \\
\hline
\end{tabular}

Broiler growth (body weight) has consistently been the prime selection trait, because of its ease of selection, high heritability and large impact on total meat production cost. There has been increasing emphasis on yields of white (breast) meat, because consumers increasingly favoured this. There was also a growing emphasis on efficiency factors, most notably feed conversion efficiency of broiler growth. The modern broilers reached almost twice the live weight on $50 \%$ less feed when compared to their performance in 1953. The greater part of these changes have resulted from genetic improvement; $85.3 \%$ for growth rate, $91.3 \%$ for carcass yield and $62.5 \%$ for feed conversion with remainder being due to diet. Family selection for livability and eradication of egg transmitted diseases at the pedigree level may have contributed to the reduction of mortality in the past, but the main contributing factors were probably better general hygiene, vaccination against common field infections and reduced disease risk during a shorter life.

The broiler performance in the United States of America from 1925 to 2016 as reported by National Chicken Council of United States is as follows [1]: (Table 3).

Table 3: Broiler performance from 1925 to 2016.

\begin{tabular}{|c|c|c|c|c|}
\hline Year & $\begin{array}{l}\text { Market Age (Average } \\
\text { Days) }\end{array}$ & $\begin{array}{l}\text { Market weight (Live } \\
\text { Weight in Pounds) }\end{array}$ & $\begin{array}{l}\text { Feed to Meat Gain (Pounds of Feed/One } \\
\text { Pound of Live Weight) }\end{array}$ & Mortality (\%) \\
\hline 1925 & 112 & 2.50 & 4.70 & 18.0 \\
\hline 1935 & 98 & 2.86 & 4.40 & 14.0 \\
\hline 1945 & 84 & 3.03 & 4.00 & 10.0 \\
\hline 1955 & 70 & 3.07 & 3.00 & 7.0 \\
\hline 1965 & 63 & 3.48 & 2.40 & 6.0 \\
\hline 1975 & 56 & 3.76 & 2.10 & 5.0 \\
\hline 1985 & 49 & 4.19 & 2.00 & 5.0 \\
\hline 1995 & 47 & 4.67 & 1.95 & 5.0 \\
\hline 2005 & 48 & 5.37 & 1.95 & 4.0 \\
\hline 2010 & 47 & 5.7 & 1.92 & 4.0 \\
\hline 2012 & 47 & 5.95 & 1.90 & 3.7 \\
\hline 2014 & 47 & 6.12 & 1.89 & 4.3 \\
\hline 2015 & 48 & 6.24 & 1.89 & 4.8 \\
\hline 2016 & 47 & 6.22 & 1.87 & 4.8 \\
\hline
\end{tabular}

Strategies for the Improvement of Breast Muscle Growth and Meat Quality Traits

The poultry industry has traditionally evaluated broiler performance based on feed conversion and body weight gain. However, strong consumer demand for breast meat yield increased its value to the industry and led poultry to look for ways to optimise breast muscle growth. The breast meat of chickens commands a high price relative to other cuts because of its low fat content and tenderness. The genetic approach has been hampered in the past because of lack of an accurate, non-destructive measure of breast meat yield in live animals. Recently several accurate non-destructive measures have been identified and used as selection tool. Initially thickness of the breast muscle was measured using needle catheters, but recently ultrasonic apparatus was employed. More expensive but accurate technique to assess the body composition of live birds was Computed Tomography scan (CT scan), Magnetic Resonance Imaging (MRI) and Echography. Ultrasound technology represents one potential strategy for the improvement of breast meat yield. Pym reported that selection based on prediction equations incorporating live weight and ultrasound measures of breast muscle viz., depth, width and length might be effective in 
increased breast meat yield in poultry. Zerehdaran reported that when indirect carcass measurements (breast muscle thickness) were applied to male selection the response for breast meat yield increased by $28.4 \%$ and combination of direct and indirect carcass measurements provided $39.1 \%$ higher response. In direct measurements, the sib information was used in index, there is higher intensity of selection which intern increases the rate of inbreeding. Whereas, indirect carcass measurements provide its own performance information for selection of candidates, which increase the accuracy of selection and consequently improve the genetic gain. It also reduces the rate of inbreeding per generation, which is desirable for long-term selection.

The ever-increasing genetic pressure to improve growth rates and breast yields of broiler chickens has led to a high incidence of several abnormalities in breast muscles during the last 20 years. However, until a few years ago, economic losses due to meat downgrading was largely counterbalanced by gains in the increasingly high growth rates of birds and greater breast meat yields. The increasing importance of technological quality of the meat in the consumer and the industry has highlighted the need for research work on the genetic control of meat characteristics, which has been seldom studied in poultry. Muscle $\mathrm{pH}$ has been associated with numerous other meat quality attributes such as colour, water holding capacity, tenderness, juiciness or shelf life. High final pH produces dark, firm and dry meat (DFD) with poor storage quality and low final $\mathrm{pH}$ produces meat with improved shelf-life but produces pale, soft and exudative (PSE) meat. The fat also influences the technological quality of the meat and also consumer preferred meat with less fat. According to the genetic parameters obtained up to now, the genetic route could efficiently improve the technological quality of meat. Indeed, heritability of quality characteristics obtained in the chicken under experimental conditions is high. At the same time, the estimated correlations do not show any genetic antagonism between the birds' performance and the quality of their meat. The ultimate $\mathrm{pH}$ could be a relevant criterion of selection because of its strong relationship to the colour, water-holding capacity or the texture of the meat.

Nowadays, the occurrence of emerging breast meat abnormalities, such as white striping and wooden breast, is associated with higher percentages of downgrading that are no longer sustainable for the poultry industry. In addition, there is also a decrease in the nutritional, sensory and technology quality of meat that may negatively impact current consumer attitudes towards poultry meat. As a consequence, should the industry consider a step back in the increase in growth rates and breast development in order to reduce the extent of the problem? The answer to this question may differ depending on the geographical market. The most vulnerable markets are those where production systems are more efficient and have higher growth rates, birds are slaughtered at higher slaughter weights/ages and the majority of poultry products are sold as whole carcasses and pieces. In such developed poultry markets, increasing the occurrence of myopathies may negatively affect consumer attitudes toward perceived animal welfare. Greater specialisation of broiler chicken hybrids following the particularities of the producing areas may be the answer. Meanwhile, the poultry industry can mitigate the negative effects of abnormalities on meat quality by modulating the growth rate of birds through farming strategies and by incorporating downgraded meat into processed products [2].

\section{Genetic strategies for ascites in broilers}

In the past fifty years consistent selection by poultry breeding companies has dramatically increased the growth rate of broiler stock. There seems to be an increase in the incidence of metabolic and physiological disorders. Among these, the as cites syndrome has been a source of concern to the poultry industry for the last decades. It has been estimated that ascites accounts for losses of about 1 billion US DOLLAR annually around the world. Ascites account for over $25 \%$ of broiler losses. The genetic selection is the best solution for eliminating the ascites syndrome in near future. Several researchers have chosen to include as cites related traits in selection programmes. As a result of selection for as cites resistance, the as cites incidence has been reduced from $43.6 \%$ to $6.4 \%$ in males and $12.3 \%$ to zero-per cent in females after two generations of selection experiment. Recent research on ascites has focused on identifying reliable, minimally invasive traits that can aid in a selection programme. With the advent of molecular genetic research on the genetic basis of ascites, we can see the potential for the identification of genetic markers that can be used to eliminate ascites from modern commercial broilers. In order to attain the goal of an ascites-free broiler, an acceptable and effective selection programme must be first developed for implementation by the poultry breeding companies.

\section{Genetic strategies for heat stress in broilers}

Heat stress is one of the most important environmental stressors challenging broiler production world-wide. The detrimental effects of heat stress on broilers range from reduced growth to decreased quality of broiler products [3]. Chickens, like all homoeothermic animals, maintain a constant body temperature over a wide range of ambient temperatures. However, when the physiological and behavioural responses to high ambient temperature are inadequate, there is a decrease in growth rate, egg production, feed efficiency, nutrient utilization and egg quality [4]. With the rapid development of the poultry industry worldwide, and especially in developing countries, importation of temperatezone high performance stocks to the less developed, hot regions is continuously increasing. The use of improper genotypes in these regions results in large economic losses due to decreased growth rate, reduced protein gain and high mortality. In general there are two ways to control the heat stress:

i. Management practices: Which involves high cost and not economical

ii. Breed broiler lines with better heat tolerance.

Three major genes associated with heat tolerance were identified in poultry and they were naked-neck gene $(\mathrm{Na})$ (reduce 
the feather coverage), frizzle gene (F) (modify the shape of the feather) and dwarf gene (dw) (reduces body size). Among these three genes, most notable is the gene for naked neck $(\mathrm{Na})$, which produces heat tolerance by reduced feather coverage thereby increasing the rate of heat dissipation.

Poultry reared under heat stress may exhibit various metabolic disorders caused by a chronic state of oxidative stress and inflammation. Recently, nuclear factor-erythroid 2-related factor 2 (Nrf2) has emerged as an agent that plays a significant role in cellular protection against oxidative stress and inflammation. The nuclear factor kappa-B (NF- $\kappa \mathrm{B})$ signalling pathway has been associated with enhanced inflammatory response and its activation has been significantly correlated with heat stress. These transcription factors when activated can regulate antioxidant and anti-inflammatory cellular responses leading to the expression of detoxifying enzymes. Studies have shown that NF- $\kappa B$ and Nrf2 expression can be modulated by several factors, such as bioactive compounds. Green tea contains many polyphenolic antioxidants including the catechin, epigallocatechin-3-gallate (EGCG). As bioactive compounds, supplementing EGCG in poultry diets may improve antioxidant status in poultry. EGCG modulates signalling pathways including the NF- $\mathrm{\kappa B}$ and Nrf2 that regulate antioxidant and anti-inflammatory responses [4].

The results of the different studies clearly demonstrated that rapid growth rate is responsible for the increasing sensitivity of broilers to high ambient temperature due to genotype-environment interaction. Therefore the increase in genetic potential of commercial broilers for fast growth under optimal conditions cannot be materialised under high ambient temperatures. Hence, specialized breeding programmes using specific indicators of adaptation to heat should be added to commercial selection programmes for rapid growth to improve broiler performance in hot climates. In this scenario, the naked neck and frizzle genes will play an important role in broiler breeding to produce heat tolerant birds.

\section{Skeletal Problems in Broilers and Selection Strategies}

Leg health has been an important component of broiler welfare and of the economy of broiler production for many decades-it encompasses a wide range of leg disorders leading to locomotion problems [5]. The aetiology of many disorders is complex and involves genetics, nutrition, growth rate, feed conversion efficiency, body conformation, exercise and stocking density. The keen competition between commercial breeding companies coupled with the high heritability of growth has resulted in a dramatic increase in the growth potential of broilers. This predisposes many skeletal defects in meat-type chickens, mainly due to rapid gain in body weight during the early growing period and the incidence was higher in male birds. Male broilers show about twice the incidence of skeletal disorders. Rapid growth may be the main factor in defects occurring up to about 4 weeks of age, after which weight produces more stress on the bones, tendons and ligaments. The present studies focuses on three skeletal disorders, namely i. Deformities of the long bones (LD), which includes valgus or varus deformation and bowed legs,

ii. Crooked toes (CT), and

iii. Tibial dyschondroplasia (TD)

Kapell et al. [5] have shown that both broiler leg health and weight have been improved in a selection program. Considerable decreases in the prevalence of leg disorders have been achieved by a strong focus on accurately scoring selection candidates and a stringent culling policy of discarding any selection candidate with clinical leg defects. In addition, predicted breeding values for candidates with non-clinical leg defects allowed the identification of families that were prone to develop leg issues. Although the heritabilities of all the leg health traits were low and their genetic correlations with body weight unfavorable but low to moderate, breeding strategies for simultaneous selection for live performance and leg health have been, and continue to be, effective. Broad breeding goals including traits related to production, welfare, adaptability, livability, and reproductive fitness are essential to achieve a balanced progress in pedigree broiler lines. This approach has had and will continue to have benefits for the broiler industry globally. In general, genetic selection appears to be a most effective means of preventing non-infectious skeletal disorders and in recent years has had a major impact on decreasing the incidence of disorders such as Tibial dyschondroplasia.

\section{Genetic strategies for layer improvement}

Egg production has always been the cornerstone of the selection criteria applied to egg laying stock. A variety of measures are known to contribute to lifetime egg production. In most cases, breeders have concentrated on egg production to approximately 500 days of age. This implies a single year production. Because all hens placed in the laying house contribute to the cost of flock, many commercial operations base their judgements on hen-housed egg production data. However, recently emphasis has been shifting to persistency of lay. As flocks maintain high rates of lay for longer periods of time, they can be kept for advanced ages without being moulted, in recent years there is an increase in use of induced moulting to extend the laying life of the hen in much parts of the world.

Egg numbers have increased from less than 270 to 340 eggs between 1950 and 1993 (28.8\% increase). This represents an average increase of about 1.8 eggs/year. Simultaneously, egg mass has been improved by $42.7 \%$, egg weight by $11.7 \%$ and feed efficiency by $32.4 \%$. Currently, in USA, the hen average flock production rate is $80 \%$, equivalent to 350 eggs per hen housed and also showed $90 \%$ livability rate during the laying period, from 16 weeks to 72 weeks. The performance of modern layers has advanced at a rate of almost three extra eggs per bird, per year. Genetics specialists in layer breeding believe that white-egg layers could ultimately produce 520 eggs as a hen-housed average and that the horizon for brown-egg strains could be 480 eggs. Such calculations give an insight into the scope for further improvement in egg production at the world level, since the current global average has been calculated at only 185 eggs produced per laying hen. 


\section{Selection strategy egg production and for feed consumption}

Traditionally part record selection has been advocated as a means of shortening generation interval to increase genetic progress. Recently apart from part-production, annual production is also taken into account for selection decision. However, use of whole record wills double the generation interval. In order to optimise genetic gain/unit of time multi-stage selection is followed as it reduces the cost and efforts (by discarding inferior birds at early age) and generation interval is minimized.

Breeders improved feed conversion throughout the 20th century by selection on increased egg mass production and smaller body size. They are the most important traits involved in variation of the feed consumption. The most commonly used criteria for feed efficiency in laying hens are daily feed intake per hen, feed intake per egg, feed conversion (kg feed per kg egg mass) and egg income minus feed cost. Pirchner noted that the prediction of feed intake from egg mass, body weight and change in body weight leaves 30$40 \%$ of the variation unexplained and this unexplained residual feed intake remains a challenge for scientists to elucidate. Hence, from mid-1980s commercial poultry geneticists have also been selecting on residual feed consumption for improving the feed efficiency. From majority of the selection experiments reported in the literature and parameters estimated from large commercial populations, it is apparent that most laying hens have a remarkable ability to adjust their feed intake to requirement. However, a significant residual component of feed intake has been shown to exist, independent of body weight and egg mass output at different ages. In recent years, because of high heritability and absence of significant negative effect on production parameters, residual feed consumption is used as selection criteria to improve the feed efficiency.

\section{Egg quality traits and its improvement strategies}

Eggshell quality has received added emphasis as a result of changing commercial practices, with minimising cracked and broken eggs in commercial systems as the eventual target. There have been a number of reports of QTL for egg shell quality traits one of which has used a relatively dense SNP approach and the most comprehensive approaches was published recently [6]. Further studies will be required to understand the genes which are responsible but combined with the transcriptomic information and genomic markers.

The cuticle is recognised as a structure which prevents the entry of microbes to the egg and Dunn [7] identified that genetics was likely to be a major factor affecting the amount of cuticle in the eggs. Most importantly, clear evidence was found which suggests that selection of the hens laying eggs with the best cuticle coverage will have less bacterial penetration [8]. This has important implications for consumer safety, reducing spoilage and reducing inter-generation transfer of microorganisms if this or related measurements are implemented in selection. The colour of eggs, although not considered important in the safety or the prevention of damage, does have a place in the marketing of the product. A completely separate breeding programme exists for the production of white and brown-shelled eggs. Genetic studies revealed high heritability of this trait and this may be of utility to breeders in creating lines with different colour characteristics to allow the production of hybrids suited to different markets.

Selection for increased egg numbers would come at the expense of egg white quality, since reducing protein concentration would be a metabolically efficient way for hens to deal with increased output. Currently quality is principally estimated using albumin height or Haugh units which have relatively high heritabilities between 0.2 and 0.5 . However, protein content would seem to be of more practical use in the processing industry and Haugh units or albumin height has a relatively poor genetic correlation with protein content. A method to estimate protein content remotely and non-destructively would be a big step in improving not only the appearance of fresh eggs but their nutritional and processing qualities. So far attempts to do this using near-infrared transmission spectroscopy and low resolution proton nuclear magnetic resonance have been relatively disappointing [9]. Other efforts to locate genetic loci for egg white properties have met some success. Identification of suitable selection criteria and carrying out genetic selection is needed to improve the albumen quality of the egg to meet the consumer demand.

The vitelline membrane is important to the egg breakout industry because of the requirement for clean separation of yolk and white. Achieving a reliable and repeatable measurement for vitelline membrane strength would seem to be a useful research objective. The sensory quality of egg yolk was the target of a programme to eradicate a defect in a gene responsible for fishy taint. The gene was identified as a flavin-containing mono-oxygenase isoform, FMO3 using a marker approach from a segregating F2 cross and by using knowledge of the trimethylamine metabolism pathway.

The trait related to aesthetics in egg is meat and blood spots, which clearly are under selectable genetic control [10]. However estimates of heritability are low (0-0.18) especially in brown egg laying hens due to the similarity of the pigments in the shell and blood and meat spots. Despite this measurement of the size of spots in relatively small samples of eggs from individual hens met with some success in reducing the overall incidence and the larger spots [11]. Because of the problem in brown egg layers searches for genetic markers or loci have been undertaken and a QTL was located for the trait on the $\mathrm{Z}$ chromosome and a putative candidate gene ZO-2 has been suggested [6]. In future, this molecular information may be incorporated in the commercial breeding programme to reduce/eliminate the incidence in the egg.

Considerable research has been made on eggshell strength and internal quality of the eggs, and improvements have been made as a result of selection. With the reintroduction of floor systems and consumer interest in processed eggs, in future more emphases have to be given to the eggshell strength and internal quality of the eggs. Practising selection for egg quality will continue to be one of the most important aspects of the breeding strategy for egg- 
laying hens. Genetics and genomics has identified new strategies to address egg quality including the use of very high density genotyping to allow genome wide selection which has potential benefits for measurements that can only be performed in one sex or late in life $[12,13]$. What remains true, whether the method of selection is traditional or modern, is that improvements in the method of measurement will always be in demand if they better measure an existing trait. Similarly if new methods of assessing quality have clear benefits they will be adopted.

\section{Poultry Welfare in Intensive and Extensive Production Systems}

Welfare has become an important element of consumers' perception of product quality. The main welfare issues for laying hens are related to the limited space and the restriction of natural behavioural expression associated with conventional cages. Indoor systems, especially laying cages, provide the safest welfare protection but extensive systems, e.g. free-range, provide more freedom and allow the widest behavioural repertoire. However, free-range systems are generally the most difficult to manage and pose the greatest welfare risks, which can sometimes be serious even causing death. Changing from conventional to enriched cages requires effective control of feather pecking and cannibalism, for both of which there are differences between breeds. Breeders are selecting against these two behavioural problems, which are more difficult to control in floor management (large groups) than in cages (small groups). Several authors have identified a hereditary basis of feather pecking behaviour, which is suggested by strain differences. Hence, selection of birds with no or very low tendency to perform feather pecking should reduce the incidence. Recently QTL involved in gentle and severe feather pecking have been identified on chicken chromosome and they may play an important role in reducing feather pecking and cannibalism in commercial layer by way of marker-assisted selection.

\section{Breeding for Diseases Resistance in Broilers and Layers}

Transboundary zoonotic diseases are serious threats to human health and the poultry economy. Outbreaks provoke concerted control efforts, including large-scale culling programmes, surveillance, vaccination and controls on the movement of animals. The highly pathogenic avian influenza (HPAI) outbreak in 2003/2004 in Thailand resulted in the loss of around 30 million birds [14]. Approximately 43 million birds were destroyed in Viet Nam in 2003/2004, and 16 million in Indonesia - roughly equivalent to $17 \%$ and $6 \%$ of the respective national populations. The major impact of disease epidemics, such as the HPAI outbreak, is market shock and ban on international trade. Non-transboundary (zoonotic or otherwise) diseases also significantly affect the economy of the poultry sector. Salmonellosis, campylobacter, Marek's disease, Newcastle disease and infectious bursal disease are among major diseases of this category. They are more or less kept under control in the commercial sector though disease control strategies which include chemotherapy, vaccination, control of disease vectors and appropriate management methods. However, there are constraints to the sustainability of such strategies. Problems include the evolution of parasite resistance to the treatments applied, such as virus resistance to vaccines (Marek's disease virus) or bacterial resistance to antibiotics. There are also concerns regarding residues in the food chain and the implications for human health of the emergence of antibiotic-resistant micro-organisms.

Recently, animal health issues are of increasing importance to all animal breeding sectors, including poultry. Though, there have been numerous studies in the past showing evidence of genetic variability of responses to various diseases of economic interest, like parasitic, bacterial or viral diseases. New opportunities have been arising thanks to major advances in animal genomics and related technologies. With the availability of the draft chicken genome sequence, the genes that underlie the resistance loci can be identified and utilized. In recent years, advances in molecular genetics have opened new vista for elucidating the relationship between genes and their corresponding phenotypes, as well as for disease prevention and control. Most research strategies are now developed, combining structural, population and functional genomics approaches.

\section{Biotechnological interventions in poultry breeding}

Now we are on the brink of a new technological development in genetic improvement of poultry such as molecular breeding. The first development that had an impact on poultry breeding was the discovery of genetic markers. Later less detailed maps had been constructed by several research groups a consensus linkage map was published in 2000 that contained almost 2,000 such genetic markers. Since March 2004 we have the first draft of the chicken genome assembly and its quality is constantly being upgraded. The latest version is available through www.ensembl.org and predicts some 24,000 genes in the chicken genome. The genome assembly of the chicken is an enormously rich resource and it is the major opening to the "black box" that contains all information on the genetic basis of poultry traits that are relevant to commercial poultry breeding. The one way of using the genome information on the chicken is to study candidate genes and another way could be to use an intermediate ("gray box") approach by exploiting the information on huge numbers of genetic markers that was indirectly derived from the sequencing effort.

We expect that over the coming years, we will see a growing number of major genes being directly selected in poultry breeding programmes. We also see aspects of genome-wide marker coverage by SNPs being applied for selected purposes. Taken together, we predict that within ten years from now selection procedures based on genomic information will be an essential part of every poultry breeding programme. We believe that such selection procedures could well turn into the core of the breeding programme. A further speculation would be that, if indeed the core of the selection programme changes over time, the structure of the programme, which is very much connected to the selection system, will also change. This will increase genetic progress and, indeed, maintenance costs of the programme, but may also provide means 
of specifically directing the flow of genes to poultry production companies. Through that route molecular breeding techniques will eventually impact on the working relationship between breeding companies and production companies. Thus, molecular breeding technology contains all aspects of what is called a breakthrough development.

With the assembly of the chicken genome a major step towards the full elucidation of all gene structures of the chicken has been made. The black box will however not be fully opened until we walk the full path from gene structure through gene function, gene expression, protein interactions, biochemical and signaling pathways, cellular function and cell-cell communication towards a complete understanding of how phenotypic performance of the chicken is regulated. To do this takes an effort that cannot be imagined today. Nevertheless, through current and future research efforts in proteomics, metabolomics and all the other "-omics" areas, knowledge of this entire field will increase exponentially as new technologies become available.

Nutrigenomics, as it is known, is an example of industry evolution as a way to address both resource issues and changing expectations. One example of nutrigenomics in practice is the use of Ecomomas E, which has demonstrated that the same gene expression pattern can be achieved even with the Vitamin E content reduced by $80 \%$ - a substantial feed cost saving. Another has been the use of Nutrigenomics to increase the rapidity in the screening on new technologies, and one of the results has been Actigen, which was fractionated from specific carbohydrates present in yeast cell wall, and which has been shown to be twice as effective in improving growth as other yeast fractions. Finally through Programmed Nutrition (PN), it is possible to use nutrigenomics to deliver diets that result in lower levels of mineral excretion, improved antioxidant status of the animal, avail of alternative feed materials, make the diet more cost effective and enhance the quality of the meat [15].

For directed gene manipulation to be workable, we also need effective and efficient technology for genetic modification of birds. This has proven to be a major hurdle in avian systems and especially the delivery of a transgene or gene construct to an avian embryo is much more complicated than in a mammalian system. Although current transgenics are focusing on applications in the pharmaceutical domain, these achievements do open the way to exploitation in poultry breeding for agricultural purposes. However, this will take a lot of time. Firstly, much more knowledge on gene action in the chicken is needed to come up with a sound proposal for genetic modification of a chicken for agricultural use. Secondly, genetic modification systems for the chicken still need major improvements.

\section{Sustainable Development Perspectives of Poultry Production}

The concept of 'sustainability' or 'sustainable development' is multi-dimensional, encompassing economic, environmental, social, and institutional governance aspects. Many sustainability aspects need to be addressed in the current poultry sector. One major challenge for the sustainability of a complex system is that it cannot be classified as 'sustainable' if one or more of its subsystem presents unsustainable challenges, e.g. feed production in environmentally and socially critical conditions. In search of solutions, there will be many cases, where potential conflicts between different priorities arise, e.g. between long term consequences versus short term costs or benefits of the production. This is illustrated by Williams et al. [16], who compared different poultry production systems and concluded that organic and non-organic systems had different aims and therefore were difficult to compare. However, the nutrient output per hectare was generally lower in organic systems, due to slower growth rates and lower livestock density. This can be seen as unsustainable, because it produces less human food using more resources. However, Leinonen et al. $[17,18]$ reported that feed seems to be the factor in poultry production that caused the largest environmental impact, being highest in organic egg and meat production compared to other systems (cage, barn or free range), due to higher feed intake, less output efficient production and poorer FCR. Some ingredients in conventional feed, however, have a high environmental impact, such as the use of non-organic soya, palm oil and pure amino acids [16].

If a production system did not rely on imported feed, poultry fitted well into a diverse farming system, with locally sourced feed, and then the slower growth of chickens and access to outdoor areas could lead to higher animal welfare, and better use of marginal areas. There may even be synergistic effects between chicken production and fruit production, for example, in terms of pest and weed management and manure to the trees on one side and better animal welfare on the other side. If poultry is integrated into selfsustaining agricultural systems, e.g. on marginal land, forest areas or fruit production areas, there can be a synergy between the different components of the farm. If not, then the need to import feed and dispose of manure adds to the environmental costs of livestock production, even though poultry has good efficiency in transforming feed to animal products [19].

Poultry has potential to be part of many systems, creating a more resilient poultry sector. This can only be achieved through adaptability and change, where farmers retain diversity and redundancy to ensure the adaptability of their production. There is potential for producing poultry in diverse rural and urban settings, where smallholders, as well as large scale animal systems can be integrated into the household and local food chains, and poultry can utilise food and plant byproducts and produce manure and protein rich food to the family and local community in return. In France, for example, the Label Rouge concept has been known for many years, and formed the original basis for the EU-regulation for organic broiler production systems [20]. This free-range production system has a high market share in France, especially for whole chickens. In addition to the Label Rouge system, other regional broilers are extensively produced several places in France such as the Bresse and Geline de Touraine chickens. This means that changes from the current poultry production systems must be introduced, such as locally adapted breeds, e.g. dual purpose breeds, and local markets. 
There are numerous potential pathways for sustainable development of poultry production. Poultry are living, sentient animals that can be well integrated into many different types of urban and rural farming systems, where they benefit from and contribute to such systems and to the livelihood of households around the globe, with special emphasis on women. Furthermore, local production provides potential for production with minimum transport and, concomitantly, minimum usage of fossil fuels. Among the terrestrial animals, poultry has the best conversion rate of feed to human food and the smallest environmental footprint in terms of energy and water use per kg meat or eggs produced [21-31].

\section{Conclusion}

The search for new measurements that more reliably reflect the traits which are the ultimate target of selection, whether it is reduction in bacterial contamination, resistance of the shell to damage or processing and nutritional qualities will be a major focus of continued research. Genomics in poultry breeding has seen notable progress with significant advancements in the development and availability of high density SNP panels in broilers and layers chickens. In addition, an array of statistical tools for incorporating genomics in routine genetic evaluations is also becoming increasingly available to poultry breeders. Initial empirical validations of genomics based genetic evaluation are encouraging and indicate this technology can provide improvements in accuracy over traditional methods. After a large amount of effort has been put into genomic technologies and a number of false dawns we appear to be closer than ever to the reality of marker assisted selection in poultry which would truly allow measurements that are hard to carry out to be included in selection programmes by using genome wide selection. While the potential benefits of the implementation of genomics are significant, it is clear that the implementation must be cost-effective, particularly in the context of an extremely competitive market. Breeders strive to deliver benefits in terms of product performance to its customers and wider stakeholders (e.g., governments and general public) around the globe.

In future genomics could well play an important role in supporting breeders in selection programmes. The only relevant qualification of this prediction is on the time scale. We predict that methods of assessing genetic variability at the genome level (DNA) rather than at the phenotypic level (measuring traits in animals) will be the basis of selective breeding within ten years. This will affect the structure of breeding programmes and also impact the integration of breeding in the poultry production system. The new knowledge of the molecular basis of poultry phenotypes that is generated along the way will be used to engineer and redesign the poultry genome with novel technologies, and genetically engineered poultry breeds will be marketed within twenty years from today.

\section{References}

1. Anon (2016) US Broiler Performance.

2. Petracci M, Mudalal S, Soglia F, Cavani C (2015) Meat quality in fastgrowing broiler chickens. World's Poultry Science Journal 71(2): 363374.
3. Song DJ, King AJ (2015) Effects of heat stress on broiler meat quality. World's Poultry Science Journal 71(4): 701-709.

4. Sahin K, Smith MO (2016) Regulation of transcription factors by the epigallocatechin-3-gallate in poultry reared under heat stress. World's Poultry Science Journal 72(2): 299-306.

5. Kapell DNRG, Hill WG, Neeteson AM, McAdam J, Koerhuis ANM, et al. (2012) Twenty-five years of selection for improved leg health in purebred broiler lines and underlying genetic parameters. Poultry Science 91(12): 3032-3043.

6. Honkatukia M, Tuiskula-HM, Ahola V, Uimari P, Schmutz M, et al. (2011) Mapping of QTL affecting incidence of blood and meat inclusions in egg layers BMC Genetics 12: 55.

7. Dunn IC (2004) Breeding strategies to improve the egg's natural defense. Worlds Poultry Science Journal 60(4): 458-468.

8. Bain MM, MacDade K, Schmutz M, Preisinger R, Waddington D, et al. (2009) The deposition of the cuticle on laying hens eggs is a moderately heritable trait. British Poultry Abstracts 5(1): 17-18.

9. Kemps BJ, De Ketelaere B, Bamelis FR, Mertens K, Decuypere EM, et al. (2007) Albumen freshness assessment by combining visible nearinfrared transmission and low-resolution proton nuclear magnetic resonance spectroscopy. Poultry Science 86(4): 752-759.

10. Lerner IM, Taylor LW, Lowry DC (1951) Selection for increased incidence of blood spots in white leghorns. Poultry Science 30: 748-757.

11. Noda K, Nakamura A, Kino K, Kato Y (2007) Genetic improvement by selection for decrease of the meat spots in Nagoya breed. Japanese Journal of Poultry Science 44(1): 17-22.

12. Albers G (2010) Genomic selection in poultry and pig breeding - a breakthrough technology? British Poultry Abstracts 6: 13.

13. Tuiskula-HM, Honkatukia M, Preisinger R, Schmutz M, de Koning DJ, et al. (2011) Quantitative trait loci affecting eggshell traits in an F(2) population. Animal Genetics 42(3): 293-299.

14. Ministry of Agriculture and Cooperatives (2005) Socio-economic impact assessment for the avian influenza crisis: gaps and links between poultry and poverty in smallholders. Department of Livestock Development, Ministry of Agriculture and Cooperatives, The Kingdom of Thailand. (FAO/TCP/RAS/3010e).

15. Connolly A (2012) A vision for 2020, the future of poultry. XXIV World's Poultry Congress 5 - 9 August - 2012, Salvador, Bahia, Brazil.

16. Leinonen I, Williams AG, Waller AH, Kyriazakis I (2013) Comparing the environmental impact of alternative protein crops in poultry diets: the consequences of uncertainty. Agricultural systems 121: 33-42.

17. Leinonen I, Williams AG, Wiseman J, Guy J, Kyriazakis I (2012) Predicting the environmental impact of chicken systems in the UK through a life cycle assessment: broiler production systems. Poultry Science 91(1): 8-25.

18. Leinonen I, Williams AG, Wiseman J, Guy J, Kyriazakis I (2012) Predicting the environmental impact of chicken systems in the UK through a life cycle assessment: egg production systems. Poultry Science 91(1): 26-40.

19. Vaarst M, Steenfeldt S, Horsted K (2015) Sustainable development perspectives of poultry production. World's Poultry Science Journal 71(4): 609-620.

20. Hermansen JE, Horsted K, Kongsted AG (2014) Meat production in organic farming. In: Dikeman M and Devine C (Eds) Encyclopedia of Meat Sciences 2e, 2: 199-203.

21. Berardinelli A, Ragni L, Giunchi A, Gradari P, Guarnieri A (2008) Physicalmechanical modifications of eggs for food-processing during storage. Poultry Science 87(10): 2117-2125.

22. Cheema MA, Qureshi MA, Havenstein GB (2003) A comprehension of the immune response of a 2001 commercial broiler with a 1957 
randombred broiler strain when fed representative 1957 and 2001 broiler diets. Poultry Science 82(10): 1519-1529.

23. Dekkers JC (2004) Commercial application of marker - and gene-assisted selection in livestock: Strategies and lessons. Journal of Animal Science 82(E-Suppl): E313-E328.

24. Elshire RJ, Glaubitz JC, Sun Q, Poland JA, Kawamoto K, et al. (2011) A Robust, Simple Genotyping-by-Sequencing (GBS) Approach for High Diversity Species. PLoS One 6(5): e19379.

25. Elson HA (2015) Poultry welfare in intensive and extensive production systems. World's Poultry Science Journal 71(3): 449-460.

26. Havenstein GB, Ferket PR, Qureshi MA (2003) Growth, liveability, and feed conversion of 1957 versus 2001 broilers when fed representative 1957 and 2001 broiler diets. Poultry Science 82(10): 1500-1508.
27. Laughlin K (2009) Temperton Fellowship Report No.15, Harper Adams University College, Newport, Shropshire, UK, England.

28. Li Y, Willer CJ, Ding J, Scheet P, Abecasis GR (2010) MaCH: using sequence and genotype data to estimate haplotypes and unobserved genotypes. Genetic Epidemiology 34(8): 816-834.

29. Nys Y, Bain M, Immerseel, Van F (2011) Improving the safety and quality of eggs and egg products, Cambridge: Woodhead Publishing, Cambridge, UK, pp. 581.

30. Van Der Laan MHP (2012) Breeding for genetic resistance to disease. World's Poultry Congress 5 - 9, Salvador, Bahia, Brazil.

31. Williams AG, Audsley E, Sandars DL (2009) A Lifecycle Approach to Reducing the Environmental Impacts of Poultry Production. Proceedings and Abstracts, $17^{\text {th }}$ European Symposium on Poultry Nutrition S4.1, p. 7. 